\title{
Measuring the Association of the Medicare and Medicaid Revenue Proportions with the Profitability of Washington Hospitals
}

\author{
Dong Yeong Shin ${ }^{1}$ and Jongwha Chang ${ }^{2 *}$ \\ ${ }^{1}$ Department Of Public Health Sciences, New Mexico State University, USA \\ ${ }^{2}$ Department Of Pharmacy Practicve, University of Texas, USA
}

*Corresponding author: Jongwha Chang, Department of Public Health Sciences, Department of Pharmaceutical Sciences, University

of Texas at El Paso, 500 W. University Ave El Paso, TX 79968

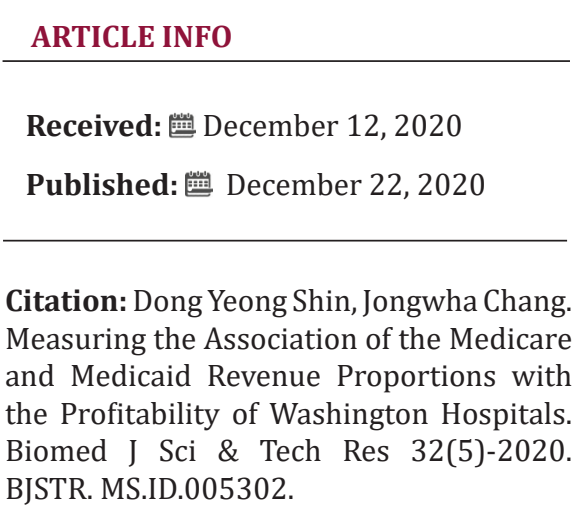

Keywords: Disproportionate Share Hospital; Medicare; Profitability; Medicaid; Reimbursement Policy
ABSTRACT

The predominant theoretical expectation of the association between government health programs (i.e., Medicare and Medicaid) and hospital profitability is that the association is adverse. However, several studies of this association have reported mixed results. The purpose of this study is to provide empirical evidence for the association of Medicare and Medicaid revenue proportion with the profitability of Washington State (WA) hospitals in 2005. This study employs multiple regression models to test established hypotheses pertinent to the association between government health programs and hospital profitability.

Key findings of this study are as follows: for WA hospitals that sustained a high proportion of Medicare and Medicaid revenue in 2005, both Medicare mix and Medicaid mix are significantly and negatively associated with hospital profitability; and, for WA hospitals with a high proportion of Medicare and Medicaid revenue that achieved profitable status in 2005, both Medicare mix and Medicaid mix are significantly and negatively associated with hospital profitability. This study suggests that further studies would provide meaningful information to hospital managers and health policymakers. Subjects recommended for further examination include employing a longitudinal design to measure the association between government health programs and hospital profitability; replicating this study using data from different states as well as data from the national level; adding categorical variables to improve the regression model; examining drivers of financial distress in the 10 unprofitable hospitals identified in this study; measuring the association between Medicaid Disproportionate Share Hospital (DSH) payments and hospital profitability; and identifying the association of case mix index and hospital profitability.

\section{Introduction}

Hospitals in the United States are reimbursed for services delivered to patients by third-party payors that can be classified broadly into four payor groups (i.e., Medicare, Medicaid, private insurance, or uninsured). According to the reimbursement policy of each third-party payor, there is the likelihood of a more or less "generous" payment pertinent to costs of hospitals' services actually used [1]. The underpayments of the Medicare and Medicaid programs combined with highly leveraged managed care organizations play a heavy role in explaining a hospital's diminished profitability, declining net worth, and increased liabilities over the market value of assets (i.e., hospital insolvencies) [2]. Since the degree of profitability of a hospital may vary by the generosity in payment of diverse payors, it has been the center of interest whether admission policies or intensity of service for patients from hospitals differ in payment policies of different payors. U.S. hospitals' various payment policy strategies are a particularly relevant issue since budget pressures from the steep ascent of hospital costs growth have made governments at all 
levels deliberate on curtailed payment rates for the Medicare and Medicaid registrants in 2001 [1].

U.S. hospitals deliver medical care to Medicaid and Medicare patients for less than cost and provide medical service to the uninsured, often for free. Hospitals have been able to provide cost-free and other under-cost services to Medicare and Medicaid registrants by shifting losses from those programs to mostly private patients [3]; these authors criticize that Medicare and Medicaid programs should provide sufficient payments for delivered services in order to prevent hospitals from shifting losses in Medicare and Medicaid services to the privately insured, and also enable hospitals to keep delivering services for the vulnerable U.S. population. Medicare and Medicaid programs, as public health insurance programs, play a role in improving access to medical care for vulnerable persons by offsetting gaps in the private health insurance market [4]. However, at the same time, they deteriorate the hospital's ability to provide services for Medicare and Medicaid registrants because these programs' inherent underpayment does not fully cover the cost of caring for the enrollees [3].

Numerous studies have attempted to identify determinants of a hospital's profitability, and it has been widely believed that a hospital's proportions of Medicare and Medicaid services are inversely associated with the profitability due to their low reimbursement rate. This belief is well supported by the majority of studies: a negative association between Medicare program and hospital profitability [5-8]; and a negative association between Medicaid program and hospital profitability [5,7-11]. However, some studies have reported mixed results for the relationship between government health programs and their effects on a hospital's profitability or cost-efficiency $[8,11]$.

The purpose of this study is to test the association of the Medicare and Medicaid revenue proportion with hospital profitability in Washington State. This study is unique because it also measures the association between the government health programs and hospital profitability by stratifying WA hospitals based on the degree of the Medicare and Medicaid revenue proportion as well as profitability status.

\section{Methods}

This study is designed as cross-sectional analytic research using secondary data analysis. Since this study employs a cross-

Table 1: Study Variables and Definitions. sectional study design, it may only measure the association of the Medicare and Medicaid revenue proportions with the profitability of Washington hospitals at a certain point of time (i.e., the fiscal year 2005). The data used in this study are 2005 fiscal year-endreports for WA hospitals retrieved from the Center for Health Statistics of the Washington State Department of Health. A fiscal year-end-report provides a hospital's aggregate financial and utilization data. This study referred to four sections in a year-endreport: hospital information, payor units of service and revenue, deductions from revenue, and income statements. The Center for Health Statistics also offers community hospital discharge data in the Comprehensive Hospital Abstract Reporting System (CHARS). The Hospital Census and Charges spreadsheet of 2005 full year CHARS standard Reports is referenced to identify each hospital's case mix index and mean length of stay.

The unit of analysis in this study is the hospital. The sample size is 96 , which is the entire study population of Washington hospitals that provided their 2005 financial data and discharge data to the Washington State Department of Health by December 2006. This study performed statistical analyses using collected data with SPSS software. This study employed three different kinds of statistical methods (i.e., descriptive statistics, correlation analysis, and linear regression). This study measured descriptive statistics to examine WA hospitals' characteristics in terms of profitability, proportions of the Medicare and Medicaid revenue, and other empirically proven predictors of hospital profitability. This study also conducted a correlation analysis to provide descriptive information for the correlations among study variables measured by data from 96 WA hospitals. As the main statistical analysis, this study performed multivariate analyses by using a linear regression model to measure the association of the proportion of the Medicare and Medicaid revenue with the profitability of Washington hospitals with a higher proportion of Medicare and Medicaid revenue in 2005.

The study employed a total of eleven variables, which consist of two dependent variables (operating margin and cash flow margin), two independent variables (Medicare mix and Medicaid mix), and control variables (case mix, DSH payment, hospital size, labor intensity, length of stay, occupancy rate, and uncompensated care mix). The operational definitions of all study variables are presented in Table 1.

\begin{tabular}{|c|c|}
\hline Variables & Definition \\
\hline \multicolumn{2}{|c|}{ Dependent Variables } \\
\hline Operating Margin & Total operating revenue - Total operating expense (Net operating Income) \\
Total operating revenue \\
\hline Cash Flow Margin & Net operating revenue + Depreciation + Interest + Lease (EBITDA) \\
& Total operating revenue \\
\hline
\end{tabular}




\begin{tabular}{|c|c|}
\hline & Independent Variables \\
\hline \multirow{2}{*}{ Medicare Mix } & Medicare revenue \\
\hline & Total patient services revenue \\
\hline \multirow{2}{*}{ Medicaid Mix } & Medicaid revenue \\
\hline & Total patient services revenue \\
\hline \multicolumn{2}{|r|}{ Control Variables } \\
\hline Case Mix & Case mix index in 2005 full year CHARS standard reports \\
\hline \multirow{2}{*}{ DSH payment } & State DSH payments \\
\hline & Total patient services revenue \\
\hline Hospital Size & Total beds available \\
\hline \multirow{2}{*}{ Labor Intensity } & Full time equivalents (FTEs) \\
\hline & Adjusted patients days \\
\hline Length of Stay & Mean length of stay day in 2005 full year CHARS standard reports \\
\hline \multirow{2}{*}{ Occupancy Rate } & Patient days \\
\hline & (Total licensed beds-Skilled nursing \& swing beds-Chemical dependency)X365 \\
\hline \multirow{2}{*}{ Uncompensated Care Mix } & Charity care deduction + Provision of bad debt expense \\
\hline & Net patient service revenue \\
\hline
\end{tabular}

\section{Results}

Table 2 provides descriptive statistics of 96 WA hospitals for the dependent variables, independent variables, and control variables. Table 3 also shows descriptive statistics about the proportion of Medicare and Medicaid revenue that is not a study variable but is a criterion used to identify WA hospitals with a high proportion of Medicare and Medicare revenue in 2005. The median values of WA hospitals' profitability in 2005 measured by operating margin and cash flow margin were 3.7 percent and 10.2 percent, respectively. The median value for total margin measured implied that a WA hospital made 3.7 cents of operating gains on every dollar of total patient service revenues in 2005. The median cash flow margin value showed that 10.2 cents on every dollar of total operating revenues were received by a WA hospital via cash in 2005. The study results indicated that the Medicare and Medicaid revenue accounted for 36.2 percent and 15.8 percent of WA hospitals' total patient services revenues in 2005, respectively. This implied that a WA hospital made twice as much money from the Medicare program as from Medicaid in 2005. The median value for the proportion of Medicare and Medicaid revenue was 58.1 percent, more specifically, 58.07 percent, and this was employed as the cutting point to define WA hospitals with a high proportion of Medicare and Medicaid revenue in 2005

Table 2: Descriptive Statistics for the Study Variables in 2005 (N=96).

\begin{tabular}{|c|c|c|c|c|}
\hline Variables (Unit) & Median & Minimum & Maximum & Std. Deviation \\
\hline Operating Margin (\%) & 3.7 & -16.4 & 25.5 & 6.3 \\
\hline Cash Flow Margin (\%) & 10.2 & -3.9 & 23.9 & 5.7 \\
\hline Medicare Mix (\%) & 36.2 & 0 & 71.5 & 12.7 \\
\hline Medicaid Mix (\%) & 15.8 & 0 & 54.8 & 12 \\
\hline $\begin{array}{l}\text { Proportion of Medicare and Medicaid revenue* } \\
(\%)\end{array}$ & 58.1 & 0 & 90.3 & 13 \\
\hline Case Mix (index) & 0.829 & 0.367 & 4.082 & 0.501 \\
\hline DSH Payment (\%) & 0.3 & 0 & 3.9 & 0.6 \\
\hline Hospital Size (beds) & 67 & 6 & 685 & 128 \\
\hline Labor Intensity (Index) & 0.016 & 0.006 & 0.096 & 0.011 \\
\hline Length of Stay (days) & 3.6 & 1.7 & 53.2 & 7.7 \\
\hline Occupancy Rate (\%) & 36.7 & 0.6 & 89.1 & 21.8 \\
\hline Uncompensated Care Mix (\%) & 6.5 & -1.7 & 28.2 & 4.8 \\
\hline
\end{tabular}

* Proportion of Medicare and Medicaid revenue is not a study variable. 
Therefore, this study defined "hospitals with a high proportion of Medicare and Medicaid revenue" as hospitals with more than 58.07 percent of Medicare and Medicaid revenue proportion in 2005. The average DSH payments aided from the state for WA hospitals accounted for 0.3 percent of total patient services revenue, and a WA hospital spent on average 6.5 percent of net patient services revenue for uncompensated care services. The median values for case mix, the number of available beds, labor intensity, length of stay, occupancy rate was 0.829 (index), 67 beds, 0.016 (index), 3.6 days, and 36.7 percent, respectively

Table 3 shows the correlations among the study variables in 2005. The results of correlation analysis showed that there was no significant correlation of dependent variables with key independent variables (i.e., Medicare mix and Medicaid mix) for WA hospitals in

Table 3: Correlation among the Study Variables in 2005 (N=96).
2005. Among the correlation analysis results, it is worthwhile to look at the correlations of the dependent variables (i.e., operating margin and cash flow margin) with the independent variables and the control variables: operating margin and cash flow margin were significantly and positively correlated with case mix index and occupancy rate; and operating margin and cash flow margin were significantly and negatively correlated with labor intensity. However, this study found the positive correlation between case mix and WA hospitals' profitability measured by either operating margin or cash flow margin in 2005, while several studies reported the negative correlation between case mix and hospital profitability [12-14]. Although this result was not supported by the abovementioned studies, the positive correlation of the dependent variables with the case mix index was also guided by suggestions of two studies $[15,16]$.

\begin{tabular}{|c|c|c|c|c|c|c|c|c|c|c|c|}
\hline & $\mathbf{O M}^{1)}$ & $\mathrm{CFM}^{2)}$ & CARE $^{3)}$ & CAID $^{4)}$ & CASE $^{5)}$ & DSH $^{6)}$ & BED $^{7)}$ & $\mathbf{L A B}^{8)}$ & LOS $^{9)}$ & $O \mathrm{OCC}^{10)}$ & $\mathrm{UNC}^{11)}$ \\
\hline $\mathrm{OM}^{1)}$ & 1 & $.900^{* * *}$ & -0.114 & 0.059 & $.282^{* *}$ & 0.016 & 0.075 & $-.259 * *$ & 0.14 & $.359 * * *$ & 0.067 \\
\hline $\mathrm{CFM}^{2)}$ & & 1 & -0.043 & -0.027 & $.278^{* *}$ & 0.003 & $.179^{*}$ & $-.267^{* *}$ & 0.05 & $.377^{* * *}$ & 0.068 \\
\hline CARE $^{3)}$ & & & 1 & $-.454^{* * *}$ & $.211^{*}$ & $-.325^{* *}$ & -0.031 & $-.275^{* *}$ & $.216^{*}$ & 0.012 & -0.041 \\
\hline $\mathrm{CAID}^{4)}$ & & & & 1 & $-.238 *$ & $.462 * * *$ & -0.162 & 0.013 & 0.054 & -0.138 & 0.102 \\
\hline $\mathrm{CASE}^{5)}$ & & & & & 1 & $-.325^{* *}$ & 0.148 & -0.163 & $.566^{* * *}$ & $.496^{* * *}$ & -0.156 \\
\hline $\mathrm{DSH}^{6)}$ & & & & & & 1 & $-.292^{* *}$ & 0.055 & $-.181^{*}$ & $-.274^{* *}$ & 0.101 \\
\hline $\mathrm{BED}^{7)}$ & & & & & & & 1 & -0.124 & -0.113 & $.525^{* * *}$ & 0.163 \\
\hline $\mathrm{LAB}^{8)}$ & & & & & & & & 1 & 0.059 & $-.413^{* * *}$ & $-.176^{*}$ \\
\hline $\operatorname{LOS}^{9)}$ & & & & & & & & & 1 & 0.117 & $-.264^{* *}$ \\
\hline $\mathrm{OCC}^{10)}$ & & & & & & & & & & 1 & 0.168 \\
\hline $\mathrm{UNC}^{11)}$ & & & & & & & & & & & 1 \\
\hline
\end{tabular}

${ }^{*} \mathrm{p}<.05 * * \mathrm{p}<.01 * * * \mathrm{p}<.001$ (one-tailed)

1) OM: Operating margin, 2) CFM: Cash flow margin, 3) CARE: Medicare mix, 4) CAID: Medicaid mix, 5) CASE: Case mix, 6) DSH: DSH payment, 7) BED: Hospital size, 8) LAB: Labor intensity, 9) LOS: Length of stay, 10) OCC: Occupancy rate, 11) UNC: Uncompensated care mix

When the operating margin was employed as a dependent variable, this study found a statistically significant and negative association between Medicare mix and operating margin of WA hospitals with a high proportion of Medicare and Medicaid revenue in 2005. This study found no evidence of a significant relationship between the Medicaid mix and operating margin of the WA hospitals in 2005; however, Medicaid mix's significance probability (.05) was marginally close to the range of statistical significance. The regression model was statistically significant $(\mathrm{P}<.05)$ and accounted for the variation in the data of 19.2 percent. This study also revealed a result of that both Medicare and Medicaid mix were significantly and negatively associated with the cash flow margin of a WA hospital with a high proportion of Medicare and Medicaid revenue in 2005. It also provided another finding for the positive association between case mix and cash flow margin of the WA hospitals with a high proportion of Medicare and Medicaid revenue in 2005 (Table 4).
This study also examined the association of Medicare and Medicaid mix with the profitability for WA hospital with a high proportion of Medicare and Medicaid revenue that achieved profitable status in 2005. This study defined "the profitable status" as "the status which achieved break-even or better financial results"; therefore, "WA hospitals with a high proportion of Medicare and Medicaid revenue that achieved profitable status in 2005 " implied hospitals which made more than $\$ 0$ of net income among WA hospitals with more than 58.07 percent of Medicare and Medicaid revenue proportion in 2005. This study found a statistically significant and negative association between Medicaid mix and operating margin of WA hospitals with a high proportion of Medicare and Medicaid revenue that achieved profitable status in 2005. However, this study found no evidence of a significant relationship between the Medicare mix and operating margin in the sample for the 2005 fiscal year (Table 5). 
Table 4: Association of the Profitability with Independent Variables and Control Variables for WA Hospitals with High Proportion of Medicare and Medicaid Revenue in 2005 (N=48).

\begin{tabular}{|c|c|c|c|c|}
\hline \multirow{3}{*}{ Variables } & \multicolumn{4}{|c|}{ Dependent Variables } \\
\hline & \multicolumn{2}{|c|}{ Operating Margin } & \multicolumn{2}{|c|}{ Cash Flow Margin } \\
\hline & Coefficient & Significance & Coefficient & Significance \\
\hline \multicolumn{5}{|c|}{ Independent Variables } \\
\hline Medicare Mix & $-.387 *$ & .043 & $-.325^{*}$ & .047 \\
\hline Medicaid Mix & -.309 & .050 & $-.344^{*}$ & .012 \\
\hline \multicolumn{5}{|c|}{ Control Variables } \\
\hline Case Mix & .055 & .128 & $.062^{*}$ & .045 \\
\hline DSH payment & .154 & .912 & .959 & .422 \\
\hline Hospital Size & .000 & .306 & .000 & .317 \\
\hline Labor Intensity & -1.358 & .399 & -1.233 & .371 \\
\hline Length of Stay & .000 & .890 & -.001 & .360 \\
\hline Occupancy Rate & .093 & .160 & .048 & .396 \\
\hline Uncompensated Care Mix & -.114 & .631 & -.103 & .613 \\
\hline $\mathrm{F}$ & \multicolumn{2}{|c|}{$2.243^{*}$} & \multicolumn{2}{|c|}{$2.755^{*}$} \\
\hline $\mathrm{R}^{2}$ & \multicolumn{2}{|c|}{.347} & \multicolumn{2}{|c|}{.395} \\
\hline Adjusted $\mathrm{R}^{2}$ & \multicolumn{2}{|c|}{.192} & \multicolumn{2}{|c|}{.252} \\
\hline
\end{tabular}

${ }^{*} \mathrm{p}<.05 * * \mathrm{p}<.01 * * * \mathrm{p}<.001$ (one-tailed)

Table 5: Association of the Profitability with Independent Variables and Control Variables for WA Hospitals with High Proportion of Medicare and Medicaid Revenue that Achieved Profitable Status in 2005 (N=38)

\begin{tabular}{|c|c|c|c|c|}
\hline \multirow{3}{*}{ Variables } & \multicolumn{4}{|c|}{ Dependent Variables } \\
\hline & \multicolumn{2}{|c|}{ Operating Margin } & \multicolumn{2}{|c|}{ Cash Flow Margin } \\
\hline & Coefficient & Significance & Coefficient & Significance \\
\hline \multicolumn{5}{|c|}{ Independent Variables } \\
\hline Medicare Mix & -.315 & .077 & $-.363^{*}$ & .028 \\
\hline Medicaid Mix & $-.385^{*}$ & .014 & $-.439 * *$ & .003 \\
\hline \multicolumn{5}{|c|}{ Control Variables } \\
\hline Case Mix & .049 & .123 & $.061^{*}$ & .038 \\
\hline Hospital Size & .000 & .074 & .000 & .060 \\
\hline Labor Intensity & -1.712 & .270 & -2.247 & .116 \\
\hline Length of Stay & .000 & .873 & -.001 & .259 \\
\hline Occupancy Rate & .045 & .455 & .022 & .687 \\
\hline Uncompensated Care Mix & .069 & .715 & 0.65 & .706 \\
\hline $\mathrm{F}$ & \multicolumn{2}{|c|}{$4.013^{* *}$} & \multicolumn{2}{|c|}{$5.155^{* * *}$} \\
\hline $\mathrm{R}^{2}$ & \multicolumn{2}{|c|}{.525} & \multicolumn{2}{|c|}{.587} \\
\hline Adjusted $\mathrm{R}^{2}$ & \multicolumn{2}{|c|}{.394} & \multicolumn{2}{|c|}{.473} \\
\hline
\end{tabular}

${ }^{*} \mathrm{p}<.05{ }^{* *} \mathrm{p}<.01{ }^{* * *} \mathrm{p}<.001$ (one-tailed)

\section{Discussion}

Although the majority of studies revealed evidence of the adverse association of hospital profitability with the Medicare and Medicaid revenue proportion, some studies reported that a hospital with higher Medicare or Medicaid proportion might be more profitable. This study paid attention to this fact, thereby attempted to measure the association of the Medicare and Medicaid revenue proportion with hospital profitability by using WA hospital data in 2005. This study also attempted to identify the change in the association of Medicare and Medicaid revenue proportion with hospital profitability when hospitals sustained a high proportion of Medicare and Medicaid revenue and when hospitals achieved profitable status despite their high proportion of Medicare and Medicaid revenue. 
For administrators of WA hospitals with a high proportion of Medicare and Medicaid revenue, this study provided a meaningful implication that the increase in the proportion of Medicare and Medicaid patient services revenue might bring financial deterioration to their hospitals. In 2005, U.S. hospitals were paid 92 cents and 87 cents for every dollar spent to deliver services for Medicare and Medicaid patients, respectively (American Hospital Association, 2006). In the same fiscal year, 21 percent of 48 WA hospitals with a high proportion of Medicare and Medicaid (i.e., 10 hospitals) could not achieve break-even in 2005. It was no wonder that those WA hospitals could not cover at least the fixed cost with their operating revenue, referring to the inherent underpayments of the Medicare and Medicaid programs.

This implication challenges those 10 WA hospitals to monitor their operating costs because the prospect of the increase in reimbursement payments from Medicare and Medicaid programs is discouraging. It is worthwhile to note that 7 out of those 10 hospitals are critical access hospitals. Executives working for those 10 unprofitable WA hospitals should be more careful in monitoring the cost level from delivering care for recipients of the Medicaid program. Indeed, this study found that Medicaid mix had a greater negative association than Medicare mix with hospital profitability measured by cash flow margin. This study, therefore, suggests that those 10 unprofitable hospitals with a high proportion of Medicare and Medicaid revenue should develop management strategies to enhance their hospital efficiency to lower operating costs, instead of counting on the likelihood of the ameliorated reimbursement environment from the government health programs in the near future.

This study found the positive association between case mix and the profitability of WA hospitals with a high proportion of Medicare and Medicaid revenue. It seems that the Medicare program played a role in contributing to the coverage in expenses and providing a reasonable degree of profitability for hospital inpatient services via cost-based reimbursements. However, ambulatory services are not paid based on resource usages but is reimbursed under the prospective payment system that a fixed payment is made on the ground of each patient's diagnosis or procedures. Therefore, acute care providers should bear financial burdens if greater services and longer lengths of stays are required by the increase in the complexity of cases.

The study finding for the positive association between case mix and hospital profitability provides a policy implication that WA hospitals that are highly dependent on Medicare and Medicaid revenue could achieve financial viability through effective inpatient case management. Referring to the fact that those WA hospitals serve vulnerable WA populations, such as the aged, the disabled, and low-income families, the elevation in their profitability is likely to contribute to the improvement in equitable and affordable access to health care in Washington State. However, since the prospective payment system weighs the burden of the case mix index in acute care providers, this study suggests that the government health program should expand cost-based payment systems to outpatient services in order to encourage hospitals providing a high proportion of Medicare and Medicaid patient services to fulfill their accountability for health care to vulnerable WA populations.

Several limitations should be considered in interpreting the findings of this study correctly. First, since this study employed the cross-sectional study design to measure the associations between the proportion of the government health programs and hospital profitability, the results only showed the association between them in a certain point of time (i.e., 2005 fiscal year); thus, the study could not account for the feasible variance in the association by the changes over time in other important factors of WA hospitals, such as long-term investments. Second, the study findings could not be generalized to hospitals in the entire United States because the associations were measured by using only WA hospital sample. Therefore, the negative association of the Medicare and Medicaid programs with the profitability of WA hospitals with a high proportion of Medicare and Medicaid revenue should not be stretched to the national level. Lastly, this study held an internal validity issue in defining the degree of a high proportion of Medicare and Medicaid revenue. This study defined WA hospitals with a high proportion of Medicare and Medicaid revenue based on the median value due to the absence of the reliable national or state criteria. Therefore, the defined WA hospitals with a high proportion of Medicare and Medicaid revenue in this study might be not necessarily hospitals with a high proportion of those from perspectives in the national level or other states level. Readers should be careful in interpreting the results of this study because the internal validity issue in defining a high proportion of Medicare and Medicaid revenue might bring about changes in samples, thereby; it might alter the results of this study as well.

\section{Conclusion}

Several research topics would provide meaningful managerial and policy implications in terms of the association between the government health programs and hospital profitability. This study would provide a more precise picture of the relationship of the Medicare or Medicaid program with hospital profitability because it would reflect long-term changes in meaningful factors that might be associated with hospital profitability. A synthesized result of these regional-specific empirical pieces of evidence for the association of government health programs and hospital profitability would be a valuable material for the federal health department to identify what would be needed to provide a better environment for the U.S. hospital industry. Further studies are needed to measure the association of the government health programs and hospital profitability in different states as well as at the national level. The comparative analyses between the state level and the national level would help health policymakers in each state to understand how 
Medicare and Medicaid programs play a role in hospital profitability differently in their state and the entire U.S. These studies would enable health policy decision-makers to develop a most suitable policy for the hospital industry in their state.

\section{References}

1. B Friedman, N Sood, K Engstrom, D McKenzie (2004) New evidence on hospital profitability by payer group and the effects of payer generosity. International Journal of Health Care Finance and Economics 4(3): 231 246.

2. W Jordan (2001) An early view of the impact of deregulation and managed care on hospital profitability and net worth. Journal of Healthcare Management 46(3): 161-172.

3. S Altman, D Shactman, E Eilat (2006) Could U.S. hospitals go the way of U.S. airlines? Health Affairs 25(1): 11-21.

4. KN Rask, KJ Rask (2000) Public insurance substituting for private insurance: New evidence regarding public hospitals, uncompensated care funds, and Medicaid. Journal of Health Economics, 19(1): 1-31.

5. W Cleverley, R Harvey (1992) Competitive strategy for successful hospital management. Hospital and Health Services Administration 37(1): 53-69

6. L Gapenski, W Vogel, B Langland-Orban (1993) The determinants of hospital profitability. Hospital \& Health Services Administration 38(1): 63-80.

7. KD Rosko (2001) Factors associated with the provision of uncompensated care in Pennsylvania hospital. Journal of Health and Human Services Administration 24(3): 352-379.

\section{ISSN: 2574-1241}

DOI: 10.26717/BJSTR.2020.32.005302

Jongwha Chang. Biomed J Sci \& Tech Res

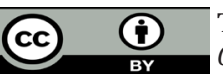

This work is licensed under Creative

Commons Attribution 4.0 License

Submission Link: https://biomedres.us/submit-manuscript.php
8. W Vogel, B Langland-Orban, L Gapenski. (1993) Factors influencing high and low profitability among hospitals. Health Care Management Review 18(2): 15-26.

9. M Cody, Lois F, ZC Hawkinson (1995) Predicting hospital profitability in short-term general community hospitals. Health Care Management Review 20(3): 77-87.

10. N McKay, M Deily (2005) Comparing high- and low-performing hospitals using risk-adjusted excess mortality and cost inefficiency. Health Care Management Review 30(4): 347-360.

11. M Rosko (2004) The supply of uncompensated care in Pennsylvania hospitals: Motives and financial consequences. Health Care Management Reviews 29(3): 229-239.

12. T Chirikos, A Sear (2000) Measurinng hospital efficiency: a comparison of two approaches. Health Services Research 34(6): 1389-1408.

13. T Li, R Rosenman (2001) Cost inefficiency in Washington hospitals: A stochastic frontier approach using panel data. Health Care Management Science 4(2): 73-81.

14. S Zuckerman, J Hadley, L Lezzoni. (1994) Measuring hospital efficiency with frontier cost functions. Journal of Health Economics 13(3): 255280.

15. K Gautam, C Campbell, A Barbara A (1995) Trends in managed care contracting among U.S. hospitals. Journal of Health Care Finance 22(2): $62-79$

16. B Langland-Orban, L Gapenski, V Vogel (1996) Differences in characteristics of hospitals with sustained high and sustained low profitability. Hospital \& Health Services Administration 41(3): 385-399.

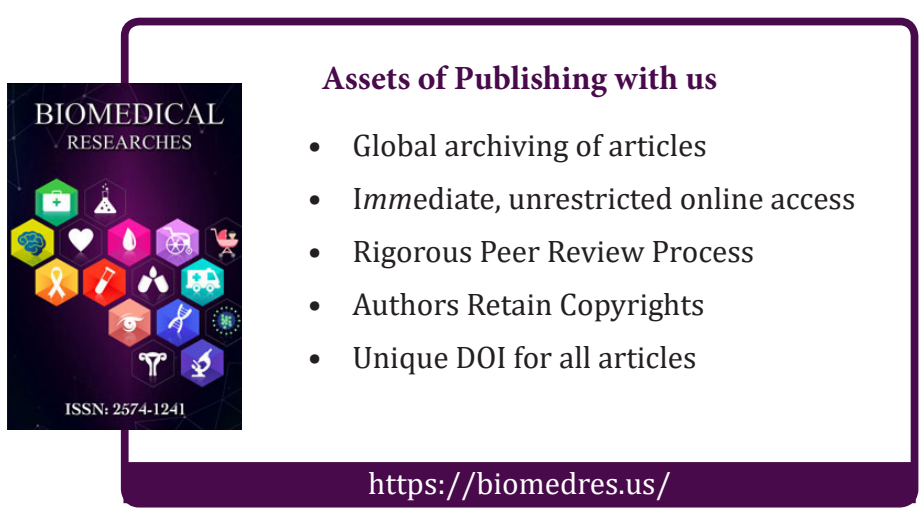

